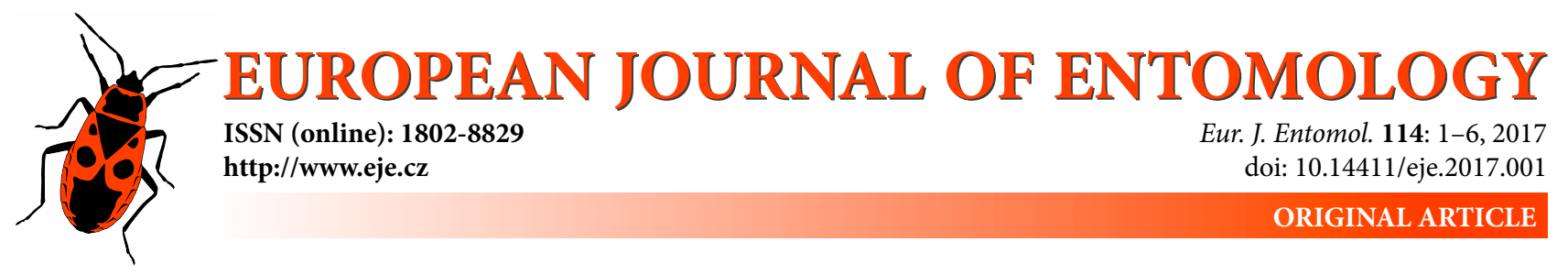

\title{
Development and survival of the spruce bark beetle, Ips typographus (Coleoptera: Curculionidae: Scolytinae) at low temperatures in the laboratory and the field
}

\author{
KRISTÝnA ŠTEFKOVÁ ${ }^{1,2}$, JAN OKROUHLÍK ${ }^{1,2}$ and PETR DOLEŽAL ${ }^{1,2}$ \\ ${ }^{1}$ Faculty of Science, University of South Bohemia, Branišovská 1760, 37005 České Budějovice, Czech Republic; \\ e-mail: kristef@seznam.cz, jan.okrouhlik@prf.jcu.cz \\ ${ }^{2}$ Biology Centre of the Academy of Sciences of the Czech Republic, Institute of Entomology, Branišovská 31, \\ 37005 České Budějovice, Czech Republic; e-mail: dolezal@entu.cas.cz
}

Key words. Coleoptera, Curculionidae, Scolytinae, Ips typographus, spruce bark beetle, development, survival, low temperature

\begin{abstract}
The European spruce bark beetle (Ips typographus) is a highly destructive pest of spruce monocultures. Adult spruce bark beetles are well-adapted to survive over winter however, the ability of sub-adult stages to overwinter has not been clearly established. The increase in average temperature recorded over the last three decades has resulted in an increase in voltinism by one generation, but due to insufficient time the last generation may not complete its development. It is crucial to investigate the survival and development of sub-adult stages at low temperatures in order to predict the effect of increased voltinism on the population dynamics of this species. We measured the development and survival of larvae and pupae (over 12 weeks) in logs kept at winter temperatures outdoors (in shade and exposed to sunlight) and in the laboratory (at 0 and $5^{\circ} \mathrm{C}$ ), with $10^{\circ} \mathrm{C}$ as a control, at which normal development was expected. Overall, findings revealed that development continued at low temperatures, although it was slower than at high temperatures. Importantly, after 12 weeks significant numbers of spruce bark beetles were present, including newly emerged adults. We demonstrate, for the first time, that sub-adult spruce bark beetles can mature over winter and the percentage survival was significant, indicating that some of the beetles that did not complete their development before the onset of winter can complete their development during winter and potentially adversely affect forests and pose problems for their management.
\end{abstract}

\section{INTRODUCTION}

In Europe, the spruce bark beetle, Ips typographus (L.) is the most destructive pest of spruce monocultures. Recent outbreaks in Central Europe have occurred following significant disturbances to forests caused by wind-storms and severe droughts (Zenáhlíková et al., 2011; Lausch et al., $2013 \mathrm{~b}$ ). An abundance of trees with little or no resistance to spruce bark beetle attack, warmer springs and summers resulting from climate change (Hansen et al., 2006), together with the ability of the bark beetle to breed rapidly in the bark of recently damaged/weakened trees, have resulted in mass attacks on neighbouring healthy trees and enormous economic losses and environmental damage (Wermelinger, 2004; Liška et al., 2016).

The speed of insect development is dependent on ambient temperature and the sum of effective temperatures, which can be used to predict population growth in the field. The sum of effective temperatures (SET) is the sum of positive differences between the diurnal mean temperature and the zero-developmental point of a given species. Zero development point is defined as the "the lower develop- mental threshold" (LDT) below which the development of an insect ceases. The SET for the complete development of the spruce bark beetle (I. typographus) ranges between 550-750 degree-days (Annila, 1969; Harding \& Ravn, 1985; Wermelinger \& Seifert, 1998; Netherer \& Pennerstorfer, 2001). Differences in SET may be explained by differences in the LDT. Temperature, therefore is a primary driver of development; it has broad effects on the internal physiology and behaviour of insects, including changes in metabolic rate, nutritional uptake, reproduction, flight activity and survival (Zaslavski, 1988). In mid to high latitudes, temperature is one of the key cues that synchronizes life cycle events with seasonal changes (Stange \& Ayres, 2010). Large scale outbreaks of bark beetles (Coleoptera: Scolytinae) are attributed to the increasingly warm and dry conditions recorded over the last two decades (Williams \& Liebhold, 2002; Lausch et al., 2013 a). A possible factor contributing to spruce bark beetle outbreaks is that with increase in temperature, overwintered insects emerge earlier in spring, filial generations develop faster and an additional generation is likely, which normally would undergo 
diapause development and overwinter (Faccoli, 2009). However, not all of the last generation complete their development before autumn and overwinter as larvae or pupae (Lombardero et al., 2000; Faccoli, 2002). Although several authors state that sub-adult stages of Ips typographus cannot successfully overwinter (Annila, 1969; Coeln et al., 1996; Jönsson et al., 2007); there is strong evidence that, despite the fact that larvae and pupae are less likely to survive than adults, nevertheless they are able to survive, especially when winters are mild (Zumr, 1982; Wermelinger \& Seifert, 1999; Faccoli, 2002; Dworschak et al., 2014). The aim of present study was therefore to investigate, over a period of 12 weeks, the development in terms of an increase in the numbers of live sub-adult beetles and concomitant decrease in numbers of larvae and pupae of Ips typographus at low temperatures (in a laboratory and at outdoor locations) in order to determine the overwintering ability of this species. Winter temperatures were varied by placing the logs outdoors in the shade and exposed to sunlight. Since it was not possible to predict accurately what outdoor temperatures would be during the study, three additional laboratory control conditions were used: 0 and $5^{\circ} \mathrm{C}$, which should mimic outdoor winter conditions, and $10^{\circ} \mathrm{C}$ at which normal development and survival is known to occur.

\section{MATERIAL AND METHODS}

\section{Experimental design}

A repeated measures experimental design with one factor, weeks, which had four levels $(0,2,6$, and 12) was used to determine development over time in each of the temperature conditions (shade, sun, 0,5 and $10^{\circ} \mathrm{C}$ ). The total number of individuals (living or dead), their developmental stage (larvae, pupae, adults) and other indicators of development such as the numbers of freshly emerged adults (pale coloured beetles) was recorded per $\mathrm{dm}^{2}$ of phloem. To determine survival, the number of live individuals (larvae, pupae, adults) per $\mathrm{dm}^{2}$ of phloem was recorded after 12 weeks. All the infested spruce logs were collected from three trees (approximately 80 years old) in November 2013 in the Šumava National Park, Czech Republic, at $1000 \mathrm{~m}$ a.s.l. Each $\log$ was approximately $50 \mathrm{~cm}$ long and $25 \mathrm{~cm}$ in diameter with similar quality bark and was similarly infested with larvae, pupae and adults of the spruce bark beetle.

\section{Sample preparation}

Logs were transported to České Budějovice and placed in the garden of the institute. Within $24 \mathrm{~h}$ of the transfer to České Budějovice, $10 \mathrm{~cm}$ wide stripes of the bark were removed from around the circumference of each log and the number of individuals and their developmental stage (larvae, pupae, adults) was recorded and recalculated in terms of area of phloem. The logs were placed into cooled incubators (Sanyo MIR 153 and 253: Sanyo Electric, Osaka, Japan) in the laboratory or outdoors (in sunlit or shaded locations). Logs were sampled and debarked and after 2, 6 and 12 weeks.

\section{Outdoor conditions}

In the garden of the Institute of Entomology in České Budějovice, seven logs were stored outdoors in an area exposed to direct sunlight and seven in the shade. During the experiment, the air temperature was recorded at hourly intervals at both outdoor locations using Cometter data loggers (Comet Systems,
Rožnov pod Radhoštěm, Czech Republic). Thermal sums were expressed as degree-days (DD) above the lower developmental threshold (LDT), which was set at $8.3^{\circ} \mathrm{C}$ for all life stages (according to Wermelinger \& Seifert, 1998) and/or to $5^{\circ} \mathrm{C}$ (according to Annila, 1969).

\section{Laboratory conditions}

A total of eighteen logs were placed in cooled incubators at constant temperatures of either 0,5 or $10^{\circ} \mathrm{C}$. The incubators were not supplied with artificial light in order to mimic the conditions of snow cover. The logs were checked twice a week and moistened with tap water to prevent the phloem drying out.

\section{Data analysis}

Statistical analyses were conducted using STATISTICA v. 12 software (StatSoft Inc., OK, USA, 2013). All data were tested for normality and homogeneity of variances using the KolmogorovSmirnov and Levene's test. To test the development over time, a series of one-way ANOVAS (Analysis of Variance) were conducted with weeks $(0,2,6,12)$ as a repeated measures factor and beetle density (measured as the number of individuals per $\mathrm{dm}^{2}$ of phloem) as the dependent variable. To test survival, the number of living individuals at 12 weeks was compared against a test statistic of zero, using a single sample t-test. In all cases, the alpha criterion for rejection of the null hypothesis was set at $p=0.05$, and all statistical tests were two-tailed, unless otherwise stated.

\section{RESULTS}

\section{Sub-imaginal development of overwintering spruce bark beetles}

In mid-November (when logs were collected), the logs contained all the developmental stages of I. typographus. The overwintering population in all the logs consisted predominantly of larvae $\left(3.3 \pm 1.5\right.$ larvae $\left./ \mathrm{dm}^{2}\right)$ and pupae $\left(4.2 \pm 1.9\right.$ pupae $\left./ \mathrm{dm}^{2}\right)$. Adults were less abundant $(1.7 \pm$ 0.6 adults $/ \mathrm{dm}^{2}$ ). Two weeks later, there was no significant differences in beetle density regardless of the temperature (cooled incubators set to $10^{\circ} \mathrm{C}, 5^{\circ} \mathrm{C}$ and $0^{\circ} \mathrm{C}$ : Fig. 1) or outdoor storage conditions (sunlit and shaded: Fig. 2). The proportions of the different developmental stages did not change, compared to that at the beginning of the experiment.

\section{Development in outdoor conditions}

The number of adults significantly increased in the logs exposed to sunlight outdoors $\left(\mathrm{F}_{3,18}=6.307, \mathrm{p}=0.004\right)$. There was an increase from $2 \pm 0.1$ adults $/ \mathrm{dm}^{2}$ (week 0 ) to $3.7 \pm 0.1$ adults $/ \mathrm{dm}^{2}$ (week 12) (Fig. 2). The differences recorded in the numbers of spruce bark beetles in the logs in the shade were not significant $\left(\mathrm{F}_{3,18}=0.23, \mathrm{p}=0.874\right)$. The only indication of possible ongoing development was the presence of newly emerged beetles $(0.5 \pm 0.07$ adults/ $\mathrm{dm}^{2}$ after 12 weeks). Daily air outdoor temperature averages during the experiment exceeded the LDT of $8.3^{\circ} \mathrm{C}$ only once (Fig. 3).

\section{Development in the laboratory}

The fastest development of beetles was recorded at a constant temperature of $10^{\circ} \mathrm{C}$, with only adult beetles present after 6 weeks (Fig. 1) and the average number of adults significantly increased from $1 \pm 0.06 / \mathrm{dm}^{2}$ at the beginning ( 0 weeks) to $4.4 \pm 0.1 / \mathrm{dm}^{2}$ at 6 weeks $\left(\mathrm{F}_{2,10}=\right.$ 


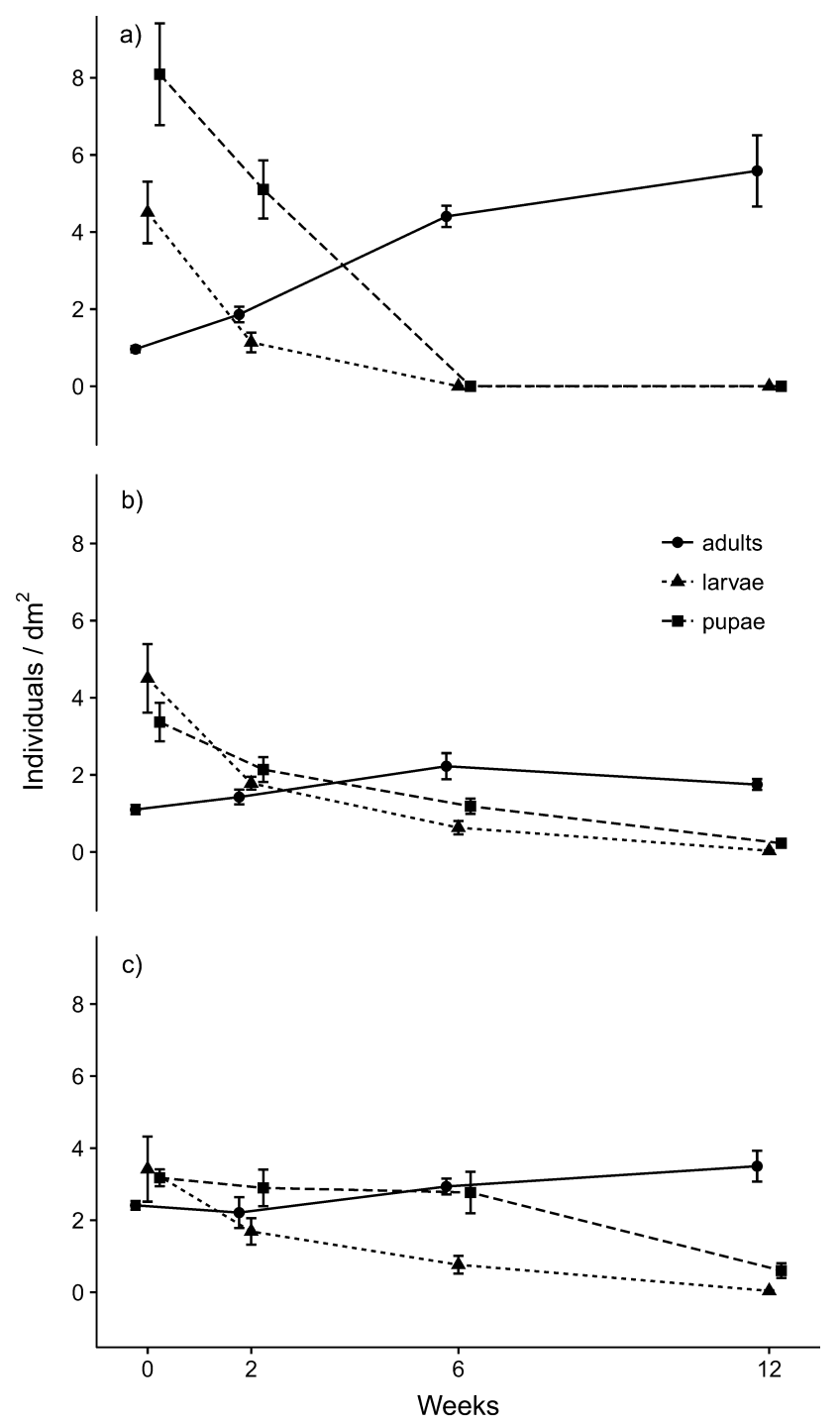

Fig. 1. The numbers of larvae, pupae and adults of the spruce bark beetle, Ips typographus, per $\mathrm{dm}^{2}$ recorded in logs kept at 10 (graph a), 5 (graph b) and $0^{\circ} \mathrm{C}$ (graph c) after $0,2,6$ and 12 weeks. Datapoints are the numbers and standard deviations recorded. Both living and dead individuals were included.

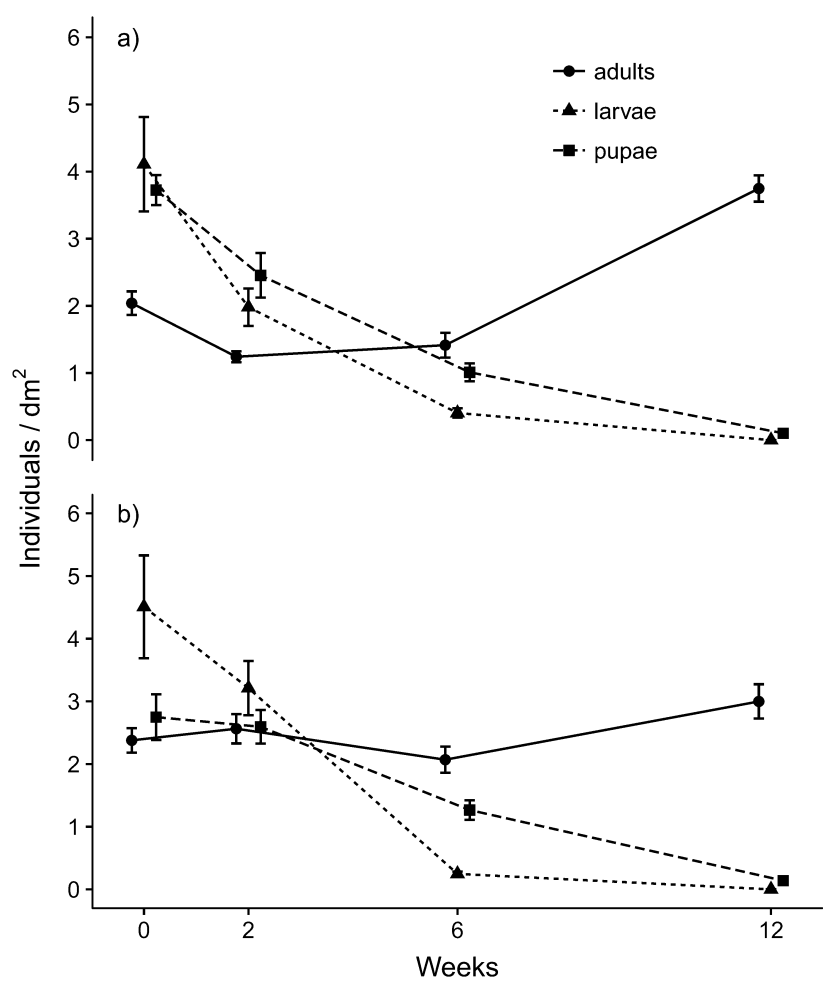

Fig. 2. The numbers of larvae, pupae and adults of the spruce bark beetle, Ips typographus, per $\mathrm{dm}^{2}$ recorded in logs kept for 0-12 weeks outdoors exposed to sunlight (graph a) and in shade (graph b) in the garden of the Institute of Entomology, České Budějovice. Data-points are the numbers and standard deviations recorded. Both living and dead individuals were included.

$8.117, \mathrm{p}=0.008)$. A marginally significant increase to $5.6 \pm$ 0.6 adults $/ \mathrm{dm}^{2}$ was recorded after 12 weeks $\left(\mathrm{F}_{3,15}=2.884\right.$, $\mathrm{p}=0.071)$ in $10^{\circ} \mathrm{C}$. At that time, newly emerged beetles made up $78 \%$ of all the adults in the logs.

No significant changes in the density of adults were recorded at $0^{\circ} \mathrm{C}\left(\mathrm{F}_{3,12}=0.539, \mathrm{p}=0.665\right)$ or $5^{\circ} \mathrm{C}$ after 12 weeks $\left(\mathrm{F}_{3,15}=0.346, \mathrm{p}=0.297\right)$. However, newly emerged beetles were recorded at both temperatures after both 6 and 12 weeks (Fig. 1). At $0^{\circ} \mathrm{C}$, the proportion of yellow col-

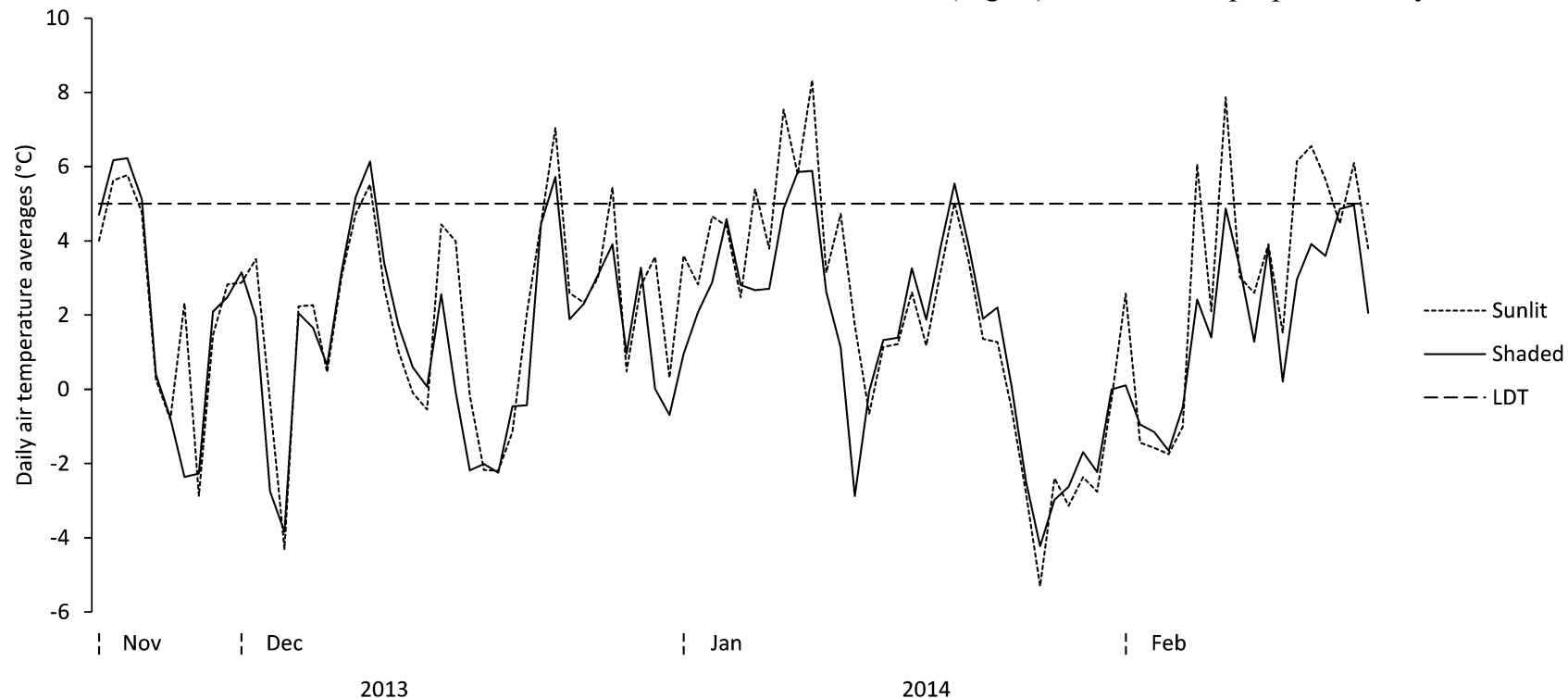

Fig. 3. Daily average air temperatures $\left({ }^{\circ} \mathrm{C}\right.$ ) recorded during the winter $2013 / 2014$ (November to February) at the two outdoor locations: $(\mathrm{A})$ exposed to sunlight, and (B) in shade. Data loggers were placed at a height of $1.5 \mathrm{~m}$ close to where the logs were kept. 


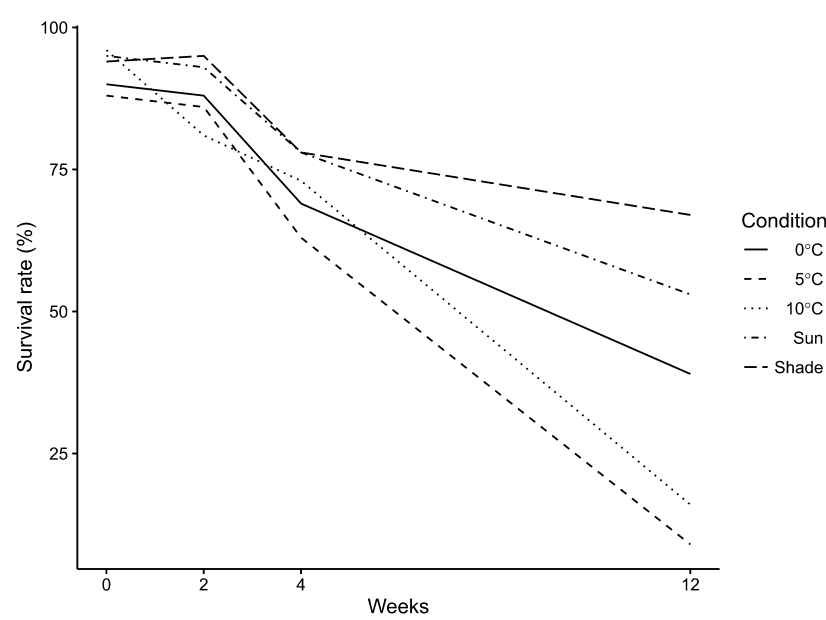

Fig. 4. The percentage of individuals alive after $0,2,4,12$ weeks when kept at either $0^{\circ} \mathrm{C}, 5^{\circ} \mathrm{C}, 10^{\circ} \mathrm{C}$ or outside exposed to sunlight and in shade.

oured adults (callow adults) increased from $0.9 \pm 0.2 / \mathrm{dm}^{2}$ at the beginning to $2.5 \pm 0.3 / \mathrm{dm}^{2}$ at the end of the experiment.

\section{Temperature-dependent survival}

Development in all the treatments was characterized by a dwindling number of larvae and a stable number of pupae (Figs 1-2). No dead larvae or their remnants (head capsules etc.) were recorded. The highest percentages of survival of all individuals (larvae, pupae, adults) was recorded in the logs kept outdoors exposed to sunlight (84\%) and in shade (79\%). The percentage survival of adults after 12 weeks was $67 \%$ in logs exposed to sunlight. In contrast, the lowest percentage survival of adults of only $9 \%$ was recorded at $10^{\circ} \mathrm{C}$ after 12 weeks (Fig. 4).

After 12 weeks, the number of live individuals (larvae, pupae and adults, both callow and mature) was recorded in each treatment $\left(0^{\circ} \mathrm{C} ; 5^{\circ} \mathrm{C} ; 10^{\circ} \mathrm{C}\right.$; sun; shade) (Table 1$)$. Table 1 shows that beetles survived in all treatments; the highest numbers of individuals were recorded in logs kept outside and exposed to sunlight, followed by those in the shade and kept at $0^{\circ} \mathrm{C}$. Smaller numbers were recorded at 5 and $10^{\circ} \mathrm{C}$. It is clear that at $0^{\circ} \mathrm{C}$ in the laboratory, and at winter outdoor temperatures, spruce bark beetles are able to survive; to test this statistically, single sample t-tests were conducted for each treatment to determine whether significant numbers of individuals survived (total number surviving). These showed that there were significant numbers of survivors in the logs in the sun $\left(\mathrm{t}_{(6)}=4.37, \mathrm{p}=0.005\right)$, in the shade $\left(\mathrm{t}_{(5)}=3.27, \mathrm{p}=0.022\right)$, at $5^{\circ} \mathrm{C}\left(\mathrm{t}_{(5)}=5.00, \mathrm{p}=0.004\right)$ and at $10^{\circ} \mathrm{C}\left(\mathrm{t}_{(6)}=2.68, \mathrm{p}=0.04\right)$, despite problems with

Table 1. Mean number of larvae, pupae, mature adults, callow adults and total number of individuals present after 12 weeks when kept at either $0^{\circ} \mathrm{C} ; 5^{\circ} \mathrm{C}$ or $10^{\circ} \mathrm{C}$ and outside exposed to sun or in shade.

\begin{tabular}{lccccc}
\hline & Larvae & Pupae & \multicolumn{2}{c}{ Dark adults Light adults } & Total \\
\hline $0^{\circ} \mathrm{C}$ & $0.2(0.45)$ & $2.6(5.81)$ & $1.6(2.07)$ & $3.6(3.65)$ & $8(7.31)$ \\
$5^{\circ} \mathrm{C}$ & $0.17(0.41)$ & $0.17(0.41)$ & $0.83(0.75)$ & $0.50(0.84)$ & $1.67(0.82)$ \\
$10^{\circ} \mathrm{C}$ & $0.00(0.00)$ & $0.00(0.00)$ & $2.14(2.12)$ & $0.00(0.00)$ & $2.14(2.12)$ \\
Sunlit spot & $0.00(0.00)$ & $0.43(0.79)$ & $8.14(4.88)$ & $2.29(4.35)$ & $10.86(6.57)$ \\
Shaded spot & $0.00(0.00)$ & $0.33(0.82)$ & $6.17(4.4)$ & $1.5(2.81)$ & $8(6)$ \\
\hline
\end{tabular}

Table 2. The sum of effective temperatures (SET) in ${ }^{\circ} \mathrm{C}$ calculated for those individuals kept at $10^{\circ} \mathrm{C}$ and outdoors exposed to sun and in shade. Both the lower developmental threshold (LDT) of $8.3^{\circ} \mathrm{C}$ (Wermelinger \& Seifert, 1998) and $5^{\circ} \mathrm{C}$ (Annila, 1969) were used.

\begin{tabular}{lcc}
\hline & \multicolumn{2}{c}{ Effective heat sums $\left({ }^{\circ} \mathrm{C}\right)$} \\
\cline { 2 - 3 } & $\mathrm{LTD}=8.3^{\circ} \mathrm{C}$ & $\mathrm{LTD}=5^{\circ} \mathrm{C}$ \\
\hline $10^{\circ} \mathrm{C}$ & 142.8 & 450 \\
Sunlit spot & 0.3 & 19.88 \\
Shaded spot & 0 & 6.86 \\
\hline
\end{tabular}

the phloem. At $0^{\circ} \mathrm{C}$, significant numbers also survived $\left(\mathrm{t}_{(4)}\right.$ $=2.45, \mathrm{p}=0.03$, one tailed). Table 1 indicates that similar numbers survived in the shade as at $0^{\circ} \mathrm{C}$ and in the sun; this was shown to be the case since (unplanned) independent t-tests showed no significant differences between shade vs. sun, or between shade vs. $0^{\circ} \mathrm{C}$ (maximum $\mathrm{t}_{(11)}=0.813$, $\mathrm{p}=0.43)$.

\section{Sum of degree-days}

Inferential analyses of sums of degree days are not presented. Having recalculated the recorded temperatures to daily averages, the averages exceeded the lower developmental threshold $\left(8.3^{\circ} \mathrm{C}\right)$ only in one case $\left(10^{\text {th }}\right.$ January 2014), in logs exposed to sunlight. At the constant temperature of $10^{\circ} \mathrm{C}$, the sum of degree days after 12 weeks reached $142.8 \mathrm{DD}$. At that time, all the spruce bark beetles had completed their development and were adults. The substitution of the LDT $8.3^{\circ} \mathrm{C}$ by LDT $5^{\circ} \mathrm{C}$ slightly increased the sums of degree days to $19.88 \mathrm{DD}$ for the logs in sunlight, 6.86 DD for those in the shade and 450 DD for those kept at $10^{\circ} \mathrm{C}$ (Table 2).

\section{DISCUSSION}

As previously documented (e.g., Zaslavski, 1988; Hui, 1994; Wermelinger \& Seifert, 1998), our experiments confirm that at constant temperatures the rate of development is dependent on temperature. As expected, at $10^{\circ} \mathrm{C}$, all larvae and pupae became adults within 6 weeks. After 12 weeks, the stage of development was not significantly different from that at 6 weeks. However, at warmer temperatures in the laboratory the mortality of newly emerged adults was high due to the drying out of the phloem (despite frequent moistening), which may have disrupted feeding. Lower temperatures of $5^{\circ} \mathrm{C}$ and $0^{\circ} \mathrm{C}$ suppressed development and immature stages were still present after 12 weeks. Howev$\mathrm{er}$, at the end of the experiment newly emerged adults were recorded at both $0^{\circ} \mathrm{C}$ and $5^{\circ} \mathrm{C}$, which indicates that development occurred at these temperatures in the laboratory. At $0^{\circ} \mathrm{C}$, the percentage of freshly emerged adults increased from $38 \%$ at the beginning (week 0 ) to $71 \%$ of all adults/ $\mathrm{dm}^{2}$ after 12 weeks. Under outdoor conditions, there was significant development of the beetles in the logs exposed to sunlight; almost exclusively only adult spruce bark beetles were recorded under the bark after 12 weeks. Contrary to previous suggestion (Wermelinger \& Seifert, 1999), the density of living adults doubled to 3.7 per $\mathrm{dm}^{2}$ in the logs exposed to sunlight. The young beetles developed predominantly from pupae because the decrease in the number of larvae was not correlated with the number of pupae. Obvi- 
ously, not all the dead larvae were recorded, which can be attributed to both unsuccessful overwintering and intraspecific competition (Lawson, 1993). Development was less apparent in the logs in shade, here, the density of adults increased, but not significantly; even so, there were freshly emerged beetles present. Air temperature did not differ between the logs exposed to sunlight and in shade, therefore such differences in development in the two outdoor treatments could be explained by solar irradiation increasing phloem temperatures resulting in faster development regardless of air temperatures (Harding \& Ravn, 1985; Baier et al., 2007; Berec et al., 2013). To summarize, there was some evidence of development in all treatments; this was most clear at $10^{\circ} \mathrm{C}$ in the laboratory and in logs exposed to sunlight outdoors. At 0 , and $5^{\circ} \mathrm{C}$, and in logs in shade, development was slower, but still occurred as newly emerged beetles were recorded.

Our findings suggest that spruce bark beetles are able to survive winter temperatures as live beetles were recorded at 0 degrees in the laboratory and more importantly in logs kept outdoors exposed to sunlight and in shade. Moreover, statistically significant numbers of beetles were recorded at 0 degrees, in the logs exposed to sunlight and in shade. Facolli (2002) records that the $49 \%$ mortality was mainly due to the death of young adults at the beginning of a harsh winter season. Dworschak (2014) records 39\% mortality for populations that consisted of immature stages. The winter mortality recorded in the study of Dworschak (2014) is based only on the number of adults recorded at the end of experiment, whereas our study included all developmental stages. When we re-calculated our results using the methods of Dworschak, our results for logs kept outdoors are similar. Our study provides clear evidence that immature spruce bark beetles can survive winter temperatures, and at numbers that are significantly different from zero.

Our results indicate that the immature stages of polyvoltine Central European populations of the spruce bark beetle can overwinter. The results also indicate that the laboratory conditions were not optimal for this beetle, because relatively few survived at 5 and 10 degrees (most likely due to the drying out of the phloem), which limited the between treatment comparisons.

It is also evident that at temperatures above zero this beetle can continue developing slowly, which is of crucial importance since it indicates that, contrary to previous thinking (Annila, 1969; Bakke, 1983; Coeln et al., 1996; Jönsson et al., 2007) immature stages may be able to survive harsh winters and therefore contribute considerably to subsequent spring infestations. The SETs required for development to the adult stage recorded in this study are lower than those recorded by previous authors (Annila, 1969; Harding \& Ravn, 1985; Wermelinger \& Seifert, 1998; Netherer \& Pennerstorfer, 2001). This discrepancy may be due to differences in the origins of the populations studied. Temperature requirements of pre-diapausing generations may differ from that of normally developing generations, which indicates the need for further studies. Moreover, winters in Scandinavia are usually much longer and colder than in Central Europe (Annila, 1969; Jönsson et al., 2007). In general, the winter $2013 / 2014$ was dry and mild. Logs were covered with snow on only two or three occasions and melted usually within a week. The average monthly temperatures were about 2 to $5^{\circ} \mathrm{C}$ above the long term averages (1961-1990).

The results of the present study indicate that immature stages of the spruce bark beetle, Ips typographus, can continue developing and successfully overwinter and may significantly contribute to spring swarming in Central Europe. Current legislation requires that infested trees are felled at the end of the vegetative season (October or November), when they are mainly infested with sub-adult spruce bark beetles, and in mountainous regions and at locations that are difficult to access (and) should be removed, at latest, the following spring. Such trees are not currently considered a threat to plantations due to the previously supposed high winter mortality of larvae and pupae. The results of this study indicate that the role of newly emerged beetles cannot be neglected and that current forestry strategy should be modified to enforce the removal of all infested timber from the forest as soon as is possible.

ACKNOWLEDGEMENTS. This study was funded by project Kontakt II LH 12098, Ministry of Education, Youth and Sports, and project 08/2009 of the Forests of the Czech Republic, state enterprises. We would like to thank V. Plchotová, E. Štefaníková for their support in the field and S. Day and R. Horsley for English revision. The authors of the manuscript would like to thank two anonymous reviewers for their comments that considerably improved the quality of this manuscript.

\section{REFERENCES}

ANNILA E. 1969: Influence of temperature upon the development and voltinism of Ips typographus L. (Coleoptera, Scolytidae). - Ann. Zool. Fenn. 6: 161-208.

Baier P., Pennerstorfer A. \& Shopf A. 2007: PHENIPS - A comprehensive menology model of Ips typographus (L.) (Col., Scolytinae) as a tool for hazard rating of bark beetle infestation. - Forest Ecol. Manag. 249: 171-186.

BAKKE A. 1983: Host tree and bark beetle interaction during mass outbreak of Ips typographus in Norway. - Z. Angew. Entomol. 96: $118-125$.

Berec L., Doležal P. \& Hais M. 2013: Population dynamics of Ips typographus in the Bohemian Forest (Czech Republic): Validation of the menology model PHENIPS and impacts of climate change. - Forest Ecol. Manag. 292: 1-9.

Coeln M., Niu Y. \& Führer E. 1996: Entwicklung von Fichtenborkenkäfern in Abhängigkeit von thermischen Bedingungen verschiedener montaner Waldstufen (Coleoptera: Scolytidae). - Entomol. Gener. 21: 37-45.

Dworschak K., Gruppe A. \& Schopf R. 2014: Survivability and post-diapause fitness in a scolytid beetle in dependence of overwintering developmental stage and implications for population dynamics. - Ecol. Entomol. 39: 519-526.

FACCOLI M. 2002: Winter mortality in sub-corticolous population of Ips typographus (Coleoptera, Scolytidae) and its parasitoids in the south-eastern Alps. - J. Pest Sci. 75: 62-68.

FACCOLI M. 2009: Effect of weather on Ips typographus (Coleoptera: Curculionidae) phenology, voltinism, and associated spruce mortality in the Southeastern Alps. - Environ. Entomol. 38: 307-316. 
Hansen J., Sato M., Ruedy R., Lo K., Lea D.W. \& MedinaELIZADE M. 2006: Global temperature change. - PNAS 103: 14288-14293.

HARDING S. \& RAVN H.P. 1985: Seasonal activity of Ips typographus L (Col. Scolytidae) in Denmark. - Z. Angew. Entomol. 99: 121-131.

Hui B.Y. 1994: Influence of temperature on the experimental population of the pine shoot beetle, Tomicus piniperda (L.) (Col., Scolytidae). - J. Appl. Entomol. 117: 190-194.

JönsSON A.M., HARDING S., BäRRING L. \& RAVN H.P. 2007: Impact of climate change on the population dynamics of Ips typographus in Southern Sweden. - Agric. Forest Meteorol. 146: $70-81$.

Lausch A., Heurich M. \& Fahse L. 2013a: Spatio-temporal infestation patterns of Ips typographus (L.) in the Bavarian Forest National Park, Germany. - Ecol. Indicat. 31: 73-81.

Lausch A., Heurich M., Gordalla D., Dobner H.J., GwillymMargianto S. \& Salbach C. 2013b: Forecasting potential bark beetle outbreaks based on spruce forest vitality using hyperspectral remote-sensing techniques at different scales. - Forest Ecol. Manag. 308: 76-89.

LAWSON S.A. 1993: Overwintering mortality of Ips grandicollis Eichh. (Col., Scolytidae) and its parasitoid, Roptrocerus xylophagorum Ratz. (Hym., Pteromalidae), in South Australia. J. Appl. Entomol. 115: 240-245.

LišKa J., KnížEK M., LubojackÝ J. \& Modlinger R. 2016: [Pests and diseases of forest plantation trees occurring in the Czech Republic in 2015.] In Knížek M. (ed.): [Insect Species Responsible for Forest Damage in the Czech Republic in 2015/2016. The Impact of Droughts on Forest Conditions.] Forestry and Game Management Research Institute, Jíloviště, pp. 13-19 [in Czech].

Lombardero M., Ayres M.P., Ayres B. \& Reeve J.D. 2000: Cold tolerance of four species of bark beetle (Coleoptera: Scolytidae) in North America. - Environ. Entomol. 29: 421-432.
Netherer S. \& Pennerstorfer J. 2001: Parameters relevant for modeling the potential development of Ips typographus (Coleoptera: Scolytidae). - Integr. Pest Manag. 6: 177-184.

StAnge E.E. \& Ayres M.P. 2010: Climate Change Impacts: Insects. In: eLS. John Wiley \& Sons, Chichester. http://www.els. net, doi: 10.1002/9780470015902.a0022555.

StatSoft Inc. 2013: STATISTICA v. 12.0. Data Analysis Software System. StatSoft Inc., Tulsa, OK.

Wermelinger B. \& SEIFERT M. 1998: Analysis of the temperature dependent development of the spruce bark beetle Ips typographus (L.) (Col., Scolytidae). - J. Appl. Entomol. 122: 185-191.

Wermelinger B. \& Seifert M. 1999: Temperature-dependent reproduction of the spruce bark beetle Ips typographus, and analysis of the potential population growth. - Ecol. Entomol. 24: 103-110.

WeRMELINGER B. 2004: Ecology and management of the spruce bark beetle Ips typographus - a review of recent research. Forest Ecol. Manag. 202: 67-82.

Williams D.W. \& LiebHold A.M. 2002: Climate change and the outbreak ranges of two North American bark beetles. - Agric. Forest Entomol. 4: 87-99.

Zaslavski V.A. 1988: Insect Development: Photoperiodic and Temperature Control. Springer, Berlin, 189 pp.

Zenáhlíková J., Svoboda M. \& Wild J. 2011: [The state and development of natural regeneration before and one year after a dieback in the tree layer of a mountain spruce forest in the Trojmezná area of the Šumava National Park.] - Silva Gabreta 17: 37-54 [in Czech with English abstr.].

ZumR V. 1982: Hibernation of spruce bark beetle, Ips typographus (Coleoptera, Scolytidae) in soil litter in natural and cultivated Picea stand. - Acta Entomol. Bohemoslov. 79: 161-166.

Received August 9, 2015; revised and accepted November 16, 2016 Published online January 11, 2017 